\title{
Green and Efficient Oxidation of Octanol by Iron Oxide Nanoparticles Supported on Activated Carbon
}

\author{
Mohammad Sadiq1", Razia Aman1, Saddam Hussain1', Muhammad Abid Zia², \\ Najeeb Ur Rahman', Mohammad Saeed ${ }^{3}$ \\ ${ }^{1}$ Department of Chemistry, University of Malakand, Khyber Pakhtunkhwa, Pakistan \\ ${ }^{2}$ Department of Chemistry, University of Education, Attock Campus, Attock, Pakistan \\ ${ }^{3}$ Department of Chemistry, GC University, Faisalabad, Pakistan \\ Email: ${ }^{*}$ mohammad sadiq26@yahoo.com, , sadiq@uom.edu.pk
}

Received 26 October 2014; revised 23 November 2014; accepted 25 December 2014

Copyright (C) 2015 by authors and Scientific Research Publishing Inc.

This work is licensed under the Creative Commons Attribution International License (CC BY). http://creativecommons.org/licenses/by/4.0/

(c) (i) Open Access

\begin{abstract}
Iron oxide nanoparticles were synthesized by precipitation method and supported on activated carbon. The catalyst thus obtained was characterized by various physicochemical techniques, and used for the liquid phase dehydrogenation/oxidation of octanol in a batch reactor at various temperatures in the range $30^{\circ} \mathrm{C}-60^{\circ} \mathrm{C}$. Maximum conversion of octanol to octanal was attained at $60^{\circ} \mathrm{C}$ in 30 min. However, with longer reaction time, the selectivity of the catalyst was found to change in favor of octene as a product. The catalyst could be recovered and reused multiple times without any decline in its catalytic performance.
\end{abstract}

Keywords

Liquid Phase, Oxidation, Dehydration, Octanol

\section{Introduction}

The oxidation of alcohol is an important reaction which is used on industrial scale for the manufacture of chemicals [1] [2]. There are hundreds of different reagents and methods available for the oxidation of alcohols. Even though these methods exist and are very applicable for a laboratory scale use, most of them share common disadvantages from an industrial point of view. Currently, mostly alcohol oxidation is performed with stoichiometric amounts of oxidants such as peroxides or high oxidation state metal oxides. These oxidants are not only ex-

\footnotetext{
*Corresponding author.
}

How to cite this paper: Sadiq, M., Aman, R., Hussain, S., Zia, M.A., Rahman, N.U. and Saeed, M. (2015) Green and Efficient Oxidation of Octanol by Iron Oxide Nanoparticles Supported on Activated Carbon. Modern Research in Catalysis, 4, 28-35. 
pensive but the processes wherein these oxidants are used generate organic and heavy metal wastes [3]. Consequently, alternative oxidants are required which are eco-friendly.

An ideal oxidant for any large-scale oxidation reaction should be easily accessible, cheap and non-toxic. The best oxidant to fit this description is molecular oxygen [4]. Currently, molecular oxygen is in use in several large-scale alcohol oxidation reactions which employ inorganic heterogeneous catalysts [5]-[13]. Typically these reactions are carried out at high temperatures and pressures, often in the gas phase. Unfortunately, these heterogeneous oxidation methods are not suitable for reactions required by fine chemical industry, where selectivity and mild reaction conditions are desired in the production of high value products.

If the stoichiometric oxidants are to be replaced by molecular oxygen, catalysts which are capable of activating molecular oxygen under mild reaction conditions and in solution phase are required. Noble metals can activate alcohols and molecular oxygen nearly at ambient conditions and produce the corresponding carbonyl compounds or carboxylic acids in high yields. The most commonly used catalysts consist of Pt or Pd as active components and $\mathrm{Bi}$ or $\mathrm{Pb}$ as promoters, on carbon and alumina supports. $\mathrm{Ru}$ and $\mathrm{Rh}$ are usually applied without promoters [14] [15]. Besides $\mathrm{Bi}$ and $\mathrm{Pb}$, a variety of other promoter metals have been suggested, including $\mathrm{Cd}$, $\mathrm{Co}, \mathrm{Cu}, \mathrm{Se}, \mathrm{Ce}, \mathrm{Te}, \mathrm{Sn}, \mathrm{Au}$, and Ru [16]-[22]. However the formation of esters instead of respective carboxylic acids, in the oxidation of primary aliphatic alcohols is a major drawback of these catalysts. Here we report our study on the performance of iron oxide nanoparticles supported on activated carbon in the aerobic oxidation of octanol to octanal.

\section{Experimental}

\subsection{General}

All the chemicals and reagents were of high purity grade (supplied by Scharlau, Spain) and used without any further purification. Nitrogen, oxygen and air were supplied by BOC Pakistan and further purified by specific filters (C.R.S.Inc.202268 \& C.R.S.Inc.202223).

\subsection{Activated Carbon}

The crushed peanut shells were soaked in 50 weight $\% \mathrm{H}_{3} \mathrm{PO}_{4}$ solution overnight at room temperature. The soaked sample was then loaded into a quartz tube and heated to $450^{\circ} \mathrm{C}$ at a heating rate of $0.5^{\circ} \mathrm{C} / \mathrm{min}$ in tube furnace under nitrogen flow $(40 \mathrm{~mL} / \mathrm{min})$ and then maintained at $450^{\circ} \mathrm{C}$ for $60 \mathrm{~min}$. The sample after cooling was washed in modified Soxhlet's apparatus, and then dried. Finally, the sample was sieved through US standard sieve (80 and 100 Mesh).

\subsection{Iron Oxide Nanoparticles Supported on Activated Carbon}

$0.5 \mathrm{M}$ solution of ammonium hydroxide and 0.1 M solution of iron nitrate (cyclohexane/iron nitrate 100:0.25) were mixed in a $250 \mathrm{~mL}$ flask. Ammoniumhydroxide solution was added drop wise to iron nitrate solution while the resulting mixture was stirred vigorously. The mixture was then kept for 5 - 9 hours to allow for aging. Upon aging, the solution turned black indicating that iron oxide nanoparticles were formed. In the next step, $4.0 \mathrm{~g}$ of activated carbon was stirred with the solution of iron oxide nanoparticles in order to obtain $10 \mathrm{wt} \%$ iron oxide nanoparticles on activated carbon. The solution was filtered and the filter cake was dried at $70^{\circ} \mathrm{C}$ overnight in an oven. Then it was calcined in muffle furnace by heating to $280^{\circ} \mathrm{C}$ at a heating rate of $0.5^{\circ} \mathrm{C} / \mathrm{min}$ and then maintaining at the same temperature for 2 hours.

\subsection{Catalytic Activity of the Catalyst}

Catalytic activity of the catalyst was tested by carrying out the reaction in a three-necked batch reactor. $0.5 \mathrm{M}$ aqueous solution of octanol $(10 \mathrm{~mL})$ and $100 \mathrm{mg}$ catalyst was loaded into a reactor and sonicated at $60^{\circ} \mathrm{C}$ in the presence of dry oxygen for $30-60 \mathrm{~min}$. The reaction mixture was then analyzed by UV spectrophotometer (UV-1800, Shimadzu, Japan) by standard addition method, and GC (Clarus 580, PerkinElmer, USA) equipped with FID.

\subsection{Characterization of Catalyst}

Iron oxide nanoparticles supported on activated carbon were characterized by SEM (JSM 5910, JEOL, Japan), 
XRD (X-ray diffractometer Rigaku D/Max-II, Cu tube, Japan), FTIR (Prestige 21 Shimadzu Japan in the range $500-4000 \mathrm{~cm}^{-1}$ ), and surface area and pore size analyzer (Quantachrome Nova 2200e, USA).

\section{Results and Discussion}

\subsection{Catalyst Characterization}

Iron oxide nanoparticles (8 - $15 \mathrm{~nm}$ ) were supported on activated carbon having particle size of 149 - $177 \mu \mathrm{m}$ (U.S. Mesh). FT-IR spectra reveal that the surface functional groups of activated carbon are: O-H, N-H (3100 $\left.3500 \mathrm{~cm}^{-1}\right)$, C-H aromatic compound (3000 $\left.-3100 \mathrm{~cm}^{-1}\right)$, C-H aliphatic compound $\left(2800-3000 \mathrm{~cm}^{-1}\right), \mathrm{C}=\mathrm{O}$ and C-O $\left(1640-1750 \mathrm{~cm}^{-1}\right)$. FT-IR of iron oxide nanoparticles supported on activated carbon shows characteristic peaks for aliphatic phosphate stretch at $1050 \mathrm{~cm}^{-1}$ and $2300 \mathrm{~cm}^{-1}$ and for hematite at $470 \mathrm{~cm}^{-1}$ and 570 $\mathrm{cm}^{-1}$ as shown in Figure 1. SEM images show a porous surface morphology of the activated carbon and also reflect the dispersion of iron oxide nanoparticles on the surface of activated carbon, as shown in Figure 2.

BET surface area of activated carbon is $1253.78 \mathrm{~m}^{2} / \mathrm{g}$ and pore volume is $0.71 \mathrm{cc} / \mathrm{g}$ while the surface area of iron oxide nanoparticles supported on activated carbon is $1235.67 \mathrm{~m}^{2} / \mathrm{g}$ and pore volume is $0.69 \mathrm{cc} / \mathrm{g}$. The decrease in surface area results probably from the blockage of surface pores of activated carbon by iron oxide nano particles. XRD results of activated carbon, and iron oxide nanoparticles supported on activated carbon are shown in Figure 3. The XRD of activated carbon shows the amorphous morphology of the activated carbon while the intense reflections in the XRD of iron oxide on activated carbon show the presence of $\gamma$-hematite nanoparticles on the surface of activated carbon.

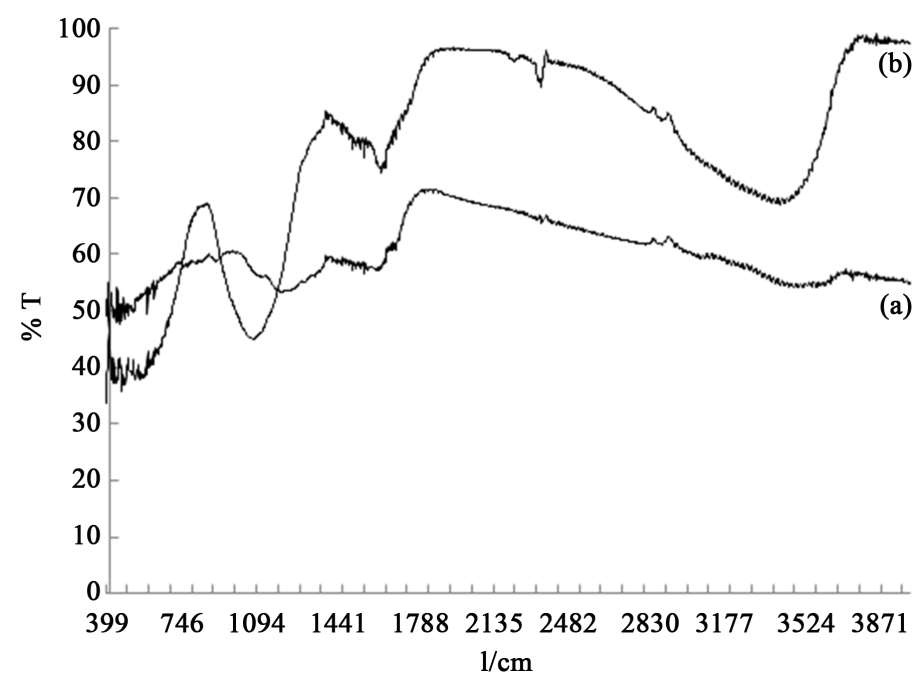

Figure 1. FT-IR spectra of (a); activated carbon (b); Iron oxide nanoparticles supported on activated carbon.

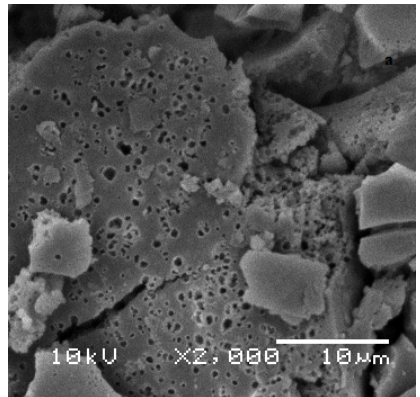

(a)

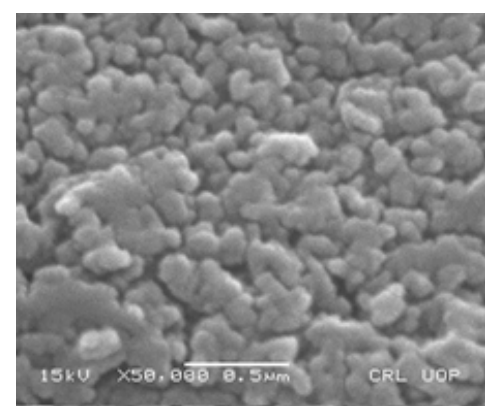

(b)

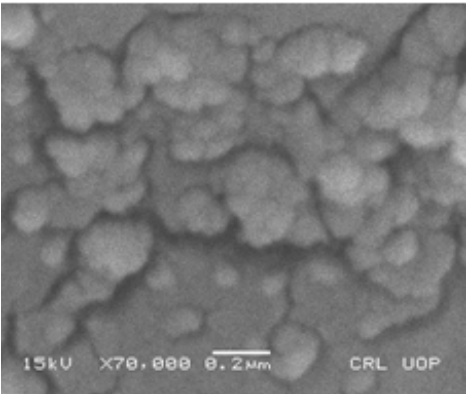

(c)

Figure 2. SEM images of (a) activated carbon; (b) iron oxide nanoparticles; (c) iron oxide nanoparticles supported on activated carbon. 


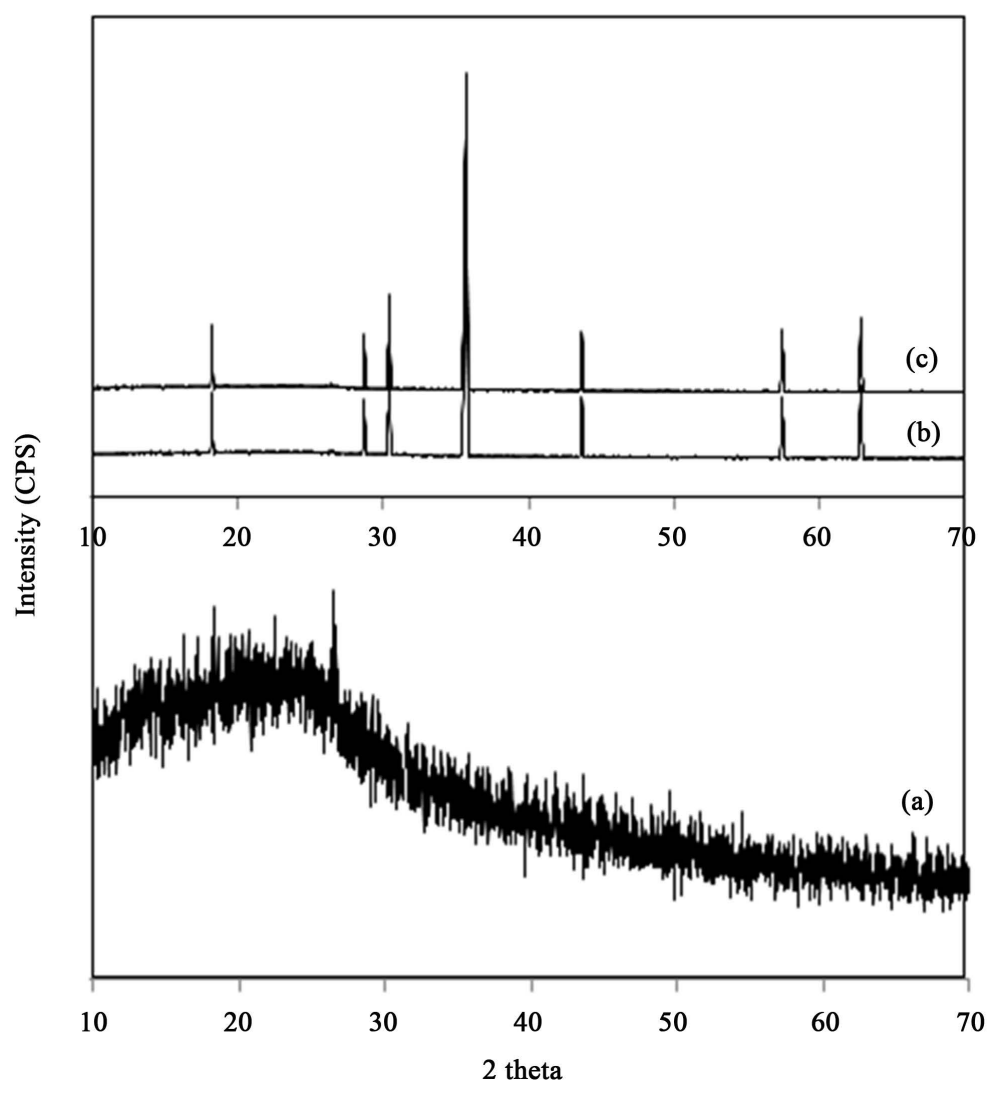

Figure 3. XRD patterns of (a) activated carbon; (b) Iron oxide nanoparticles; (c) Iron oxide nanoparticles supported on activated carbon.

\subsection{Catalytic Activity of Catalyst}

To assess the activity of the catalyst, liquid phase dehydrogenation/oxidation of octanol to octanal was carried out in a batch reactor in the presence of the catalyst under conditions as depicted in Scheme 1.

The results obtained for the reaction carried out under various conditions are presented in Table 1 . The results show that the reaction with activated carbon as a catalyst was totally selective for the dehydration of octanol to octene with a very low \% conversion. However, with $\mathrm{Fe}_{2} \mathrm{O}_{3} / \mathrm{AC}$, the reaction was impressively selective for the oxidation of octanol to octanal. The discussion hereafter is only devoted to reactions catalyzed by $\mathrm{Fe}_{2} \mathrm{O}_{3} / \mathrm{AC}$. Reaction conditions were optimized by varying one parameter at a time while others kept constant. The effect of the partial pressure of oxygen was studied at $60^{\circ} \mathrm{C}$ and it was found that the rate of reaction raised linearly as the partial pressure of oxygen was increases, while the selectivity of the catalyst for octanal declined with an increase in the partial pressure of oxygen. Study of the effect of temperature revealed that there was an inverse relation between the reaction temperature and the selectivity of the catalyst for octanal. At constant temperature and $\mathrm{pO}_{2}$, it was observed that as the reaction duration was extended, selectivity of the catalyst for octanal declined. A plot of $\ln _{\mathrm{o}} / \mathrm{C}_{\mathrm{t}} \mathrm{VS}$ time where $\left(\mathrm{C}_{\mathrm{o}}=\right.$ initial concentration while $\mathrm{C}_{\mathrm{t}}=$ final concentration $)$ as shown in the Figure 4 has a sharp linearity with a regression value of 0.997 , which suggests that the reaction is of first order.

\subsubsection{Mechanism}

The experimental data reveals that the kinetics of dehydrogenation/oxidation of octanol to octanal over iron oxide nanoparticles supported on activated carbon follows Langmuir-Hinshelwood mechanism. Rates of dehydrogenation/oxidation of octanol at various partial pressures of oxygen were calculated and subjected to analysis through various equations to investigate whether the reaction is kinetically or diffusion controlled. A reaction is kinetically controlled when its activation energy is above $25 \mathrm{~kJ} / \mathrm{mol}$. Activation energy of $51.1 \mathrm{~kJ} / \mathrm{mol}$ for the 


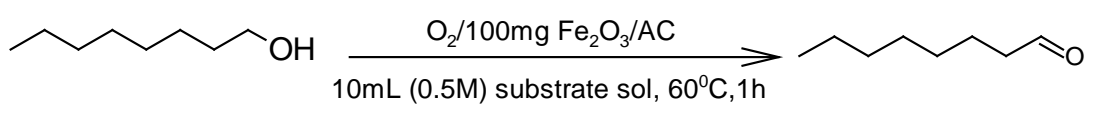

Scheme 1. Liquid phase oxidative dehydrogenation/oxidation of octanol to octanal.

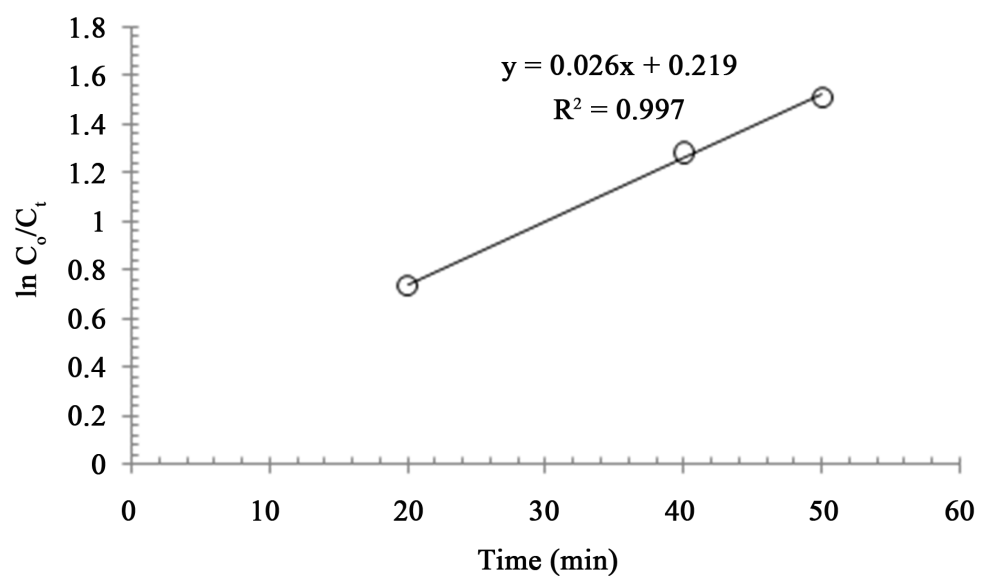

Figure 4. Plot of $\ln \mathrm{C}_{\mathrm{o}} / \mathrm{C}_{\mathrm{t}}$ Vs time (min). Reaction conditions: Substrate solution: $10 \mathrm{~mL}$; catalyst: $100 \mathrm{mg} ; \mathrm{pO}_{2}$ : 152 Torr; Temp: $60^{\circ} \mathrm{C}$.

Table 1. Catalytic performance of iron oxide nanoparticles supported on activated carbon in the oxidative dehydrogenation of octanol.

\begin{tabular}{|c|c|c|c|c|c|c|c|}
\hline \multirow{2}{*}{ Catalyst } & \multirow{2}{*}{ Pressure (Torr) } & \multirow{2}{*}{$\begin{array}{c}\text { Temperature } \\
\left({ }^{\circ} \mathrm{C}\right)\end{array}$} & \multirow{2}{*}{$\begin{array}{c}\text { Duration } \\
\text { (minutes) }\end{array}$} & \multirow{2}{*}{$\begin{array}{c}{ }^{*} \text { Conversion } \\
(\%)\end{array}$} & \multirow{2}{*}{$\begin{array}{l}\text { Rate of reaction } \\
\text { (\% conv/g/min) }\end{array}$} & \multicolumn{2}{|c|}{ Selectivity (\%) } \\
\hline & & & & & & Octanal & Octene \\
\hline AC & 190 & 60 & 60 & 3.2 & 0.05 & 0 & 100 \\
\hline \multirow{13}{*}{$\mathrm{Fe}_{2} \mathrm{O}_{3} / \mathrm{AC}$} & 38 & \multirow{5}{*}{60} & \multirow{5}{*}{60} & 15.7 & 0.26 & 100 & 0 \\
\hline & 76 & & & 39 & 0.65 & 100 & 0 \\
\hline & 114 & & & 55.5 & 0.925 & 98 & 2 \\
\hline & 152 & & & 78 & 1.30 & 95 & 5 \\
\hline & 190 & & & 97.5 & 1.62 & 85 & 15 \\
\hline & \multirow{4}{*}{152} & 30 & \multirow{4}{*}{60} & 36 & 0.6 & 100 & 0 \\
\hline & & 40 & & 45 & 0.75 & 100 & 0 \\
\hline & & 50 & & 55.2 & 0.92 & 98.5 & 1.5 \\
\hline & & 60 & & 78 & 1.30 & 95 & 5 \\
\hline & \multirow{4}{*}{152} & \multirow{4}{*}{60} & 20 & 52.1 & 0.86 & 100 & 0 \\
\hline & & & 30 & 61.9 & 1.03 & 100 & 0 \\
\hline & & & 40 & 72.4 & 1.20 & 98 & 2 \\
\hline & & & 50 & 78 & 1.30 & 96.4 & 3.6 \\
\hline
\end{tabular}

a) Reaction conditions: $10 \mathrm{~mL}$ of substrate solution, $0.1 \mathrm{~g}$ catalyst; b) ${ }^{*}$ (calculated from remaining alcohol).

reaction in focus as calculated by using Arrhenius equation ( $\ln$ rate $=\ln A-E a / R T)$ thus confirms that the reaction was kinetically controlled, as shown in Figure 5.

The Langmuir-Hinshelwood equation for weak molecular adsorption is

$$
\text { rate }=\mathrm{kpO}_{2}
$$

The experimental data when fitted into Equation (1) gave a sharp linearity, with a regression value of 0.997, as shown in Figure 6.

The data was then analyzed through L-H kinetic equation for the dissociative adsorption as given below:

$$
\text { rate }=\frac{k K\left(\mathrm{pO}_{2}\right)^{1 / 2}}{1+K\left(\mathrm{pO}_{2}\right)^{1 / 2}}
$$




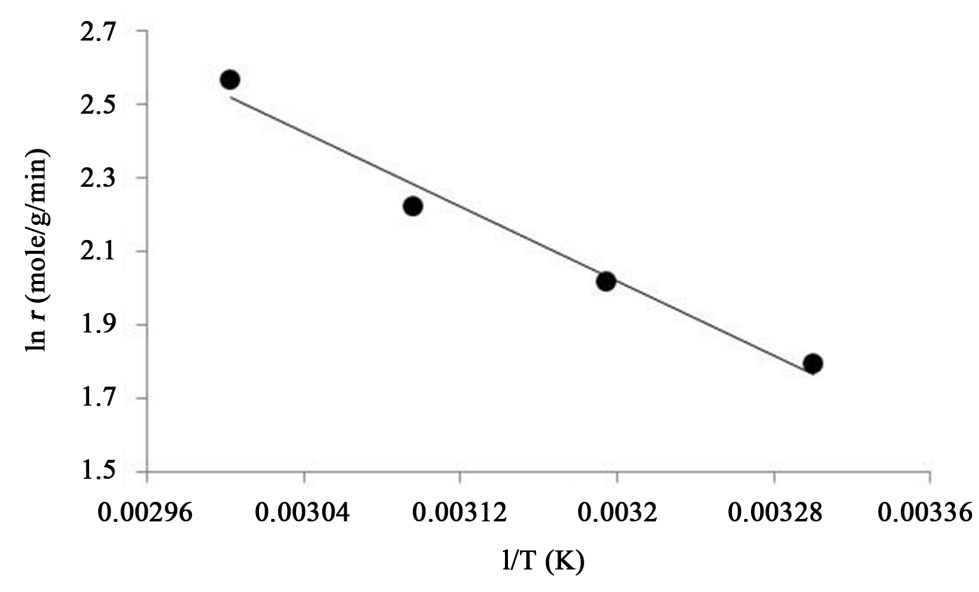

Figure 5. Arrhenius plot for activation energy. Reaction conditions: Duration: 60min; substrate solution: $10 \mathrm{~mL}$; catalyst: $100 \mathrm{mg}$; $\mathrm{pO}_{2}$ : 152 Torr.

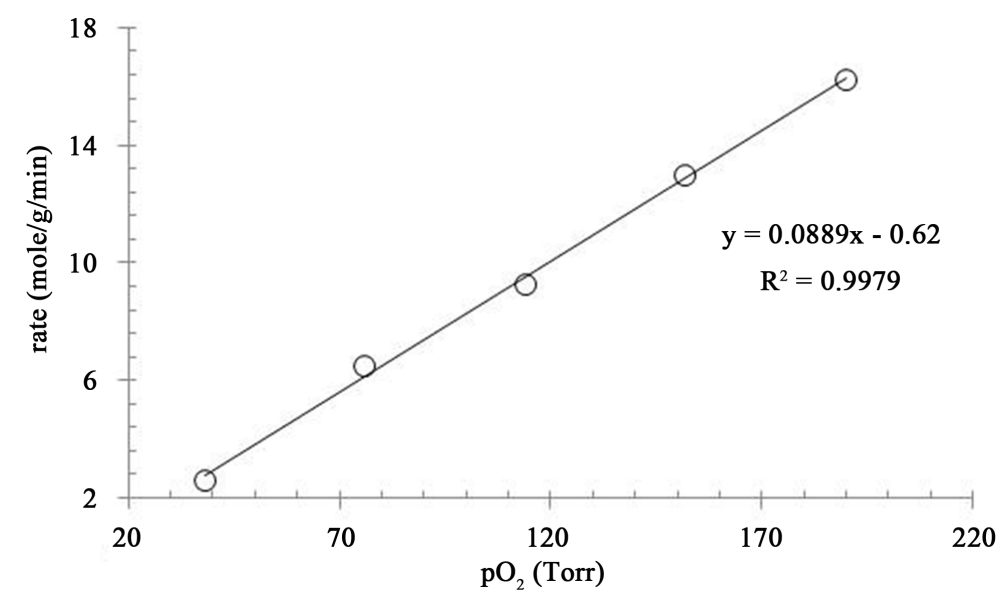

Figure 6. Linear transformation of data for oxidative dehydrogenation of octanol over iron oxide nanoparticles supported on activated carbon, according to Langmuir-Hinshelwood Equation (1). Reaction conditions: Duration: 60 min; substrate solution: $10 \mathrm{~mL}$; catalyst: $100 \mathrm{mg}$; Temp: $60^{\circ} \mathrm{C}$.

The data when fitted into Equation (2) did not give a sharp trend as shown in Figure 7; the regression value was 0.9878 . The data was also analyzed through kinetic equation for non-dissociative adsorption (L-H);

$$
\frac{\mathrm{pO}_{2}}{\text { rate }}=\frac{1}{k K+\mathrm{pO}_{2}}
$$

Equation (3) was not applicable to the experimental data, i.e., the data could not be fitted into Equation (3). Hence, we were led to conclude that the reaction proceeded with L-H mechanism for weak adsorption in comparison to L-H mechanism for dissociative adsorption.

\subsubsection{Catalyst's Life Span}

The catalyst was recycled and reused several times to test its reusability and life span. After five successive runs, no decrease in the catalytic activity of the catalyst was found. The results of these trials are shown in Figure 8. It is worth-mention that all the runs were carried out under a same set of conditions as given under Figure 8.

\section{Conclusion}

The catalytic activity of iron oxide nanoparticles supported on activated carbon was investigated for the liquid 


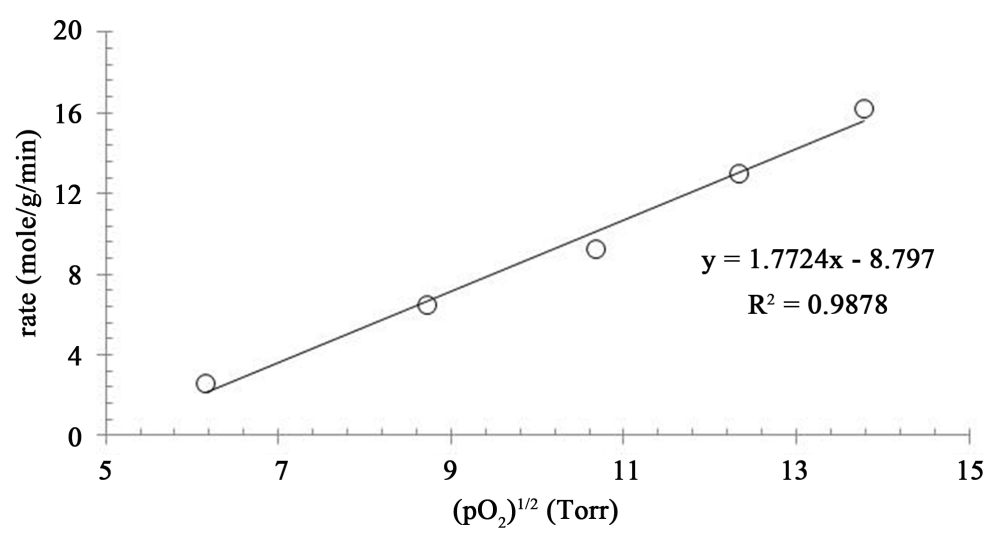

Figure 7. Linear transformation of data for oxidative dehydrogenation of octanol over iron oxide nanoparticles supported on activated carbon according to Langmuir-Hinshelwood kinetic Equation (2). Reaction conditions: Duration: $60 \mathrm{~min}$; substrate solution: $10 \mathrm{~mL}$; catalyst: $100 \mathrm{mg}$; Temp: $60^{\circ} \mathrm{C}$.

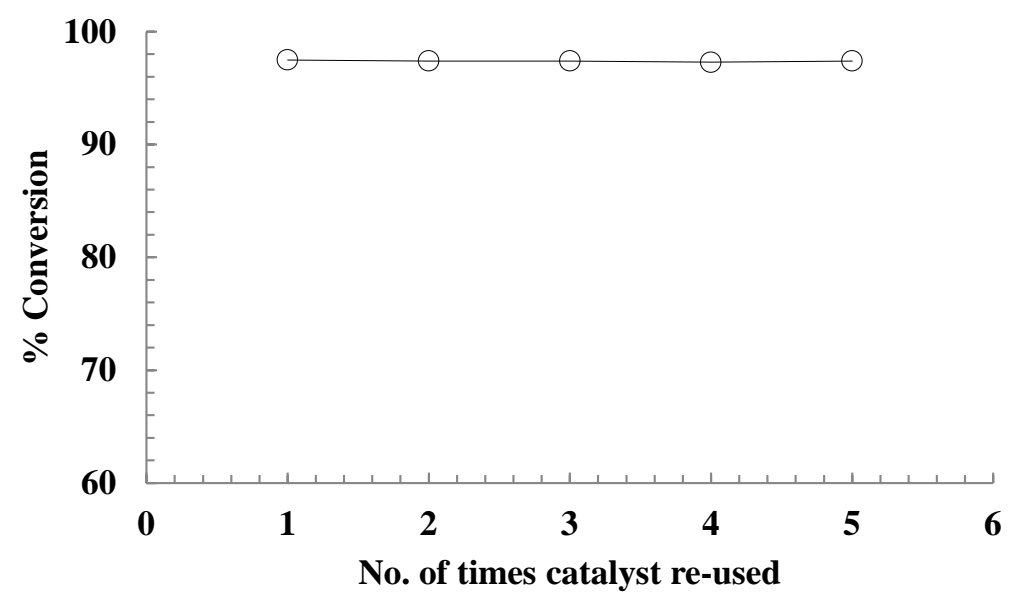

Figure 8. Re-use of catalyst for oxidation of octanol. Reaction conditions: Duration: $60 \mathrm{~min}$; substrate solution: $10 \mathrm{~mL}$; catalyst: $100 \mathrm{mg}$; $\mathrm{pO}_{2}$ : $190 \mathrm{Torr}$; Temp: $60^{\circ} \mathrm{C}$.

phase oxidation of octanol to octanal under various reaction conditions. The catalyst showed maximum selectivity for octanal at lower temperature and lower partial pressure of oxygen. The optimal conditions for the desired conversion were found to be: reaction duration (60 min), partial pressure of oxygen (152 Torr), temperature $\left(60^{\circ} \mathrm{C}\right)$, catalyst $(100 \mathrm{mg})$, and $0.5 \mathrm{M}$ aqueous solution of substrate $(10 \mathrm{~mL})$. The kinetic studies showed that the reaction proceeded with first order kinetics, and followed Langmuir-Hinshelwood mechanism for weak molecular adsorption. To conclude, the catalyst has all the characteristics of being a truly heterogeneous one; it can be easily recovered by simple filtration and reused several times without loss of catalytic activity.

\section{Acknowledgements}

The authors greatly acknowledge the financial support from High Education Commission of Pakistan, Pakistan Science Foundation and University of Malakand.

\section{References}

[1] Parshall, G. and Ittel, S., Eds. (1992) Homogeneous Catalysis. 2nd Edition, John Wiley \& Sons, Inc., Hoboken.

[2] Cornils, B. and Herrmann, W., Eds. (1996) Applied Homogeneous Catalysis with Organometallic Compounds. Vol. 1, VCH, Chapter 2.4. http://dx.doi.org/10.1002/9783527619351 
[3] Anastas, P. and Warner, J. (1997) Green Cemistry: Theory and Practice. Oxford University Press, Oxford.

[4] Puzari, A. and Baruah, J. (2002) Organic Oxidative Reactions Mediated by Copper. Journal of Molecular Catalysis A: Chemical, 187, 149-162. http://dx.doi.org/10.1016/S1381-1169(02)00273-X

[5] Gates, B. (1992) Catalytic Chemistry. John Wiley \& Sons, Inc., Hoboken.

[6] Santhanaraj, D., Suresh, C., Vijayan, P., Venkatathri, N. and Shanthi, K. (2010) Mn-MCM-41 Molecular Sieves: A Selective Gas-Phase Cyclohexanol Oxidation Catalyst. Reaction Kinetics and Catalysis Letters, 99, 439-346

[7] Jasinska, E., Krzyzynska, B. and Kozlowski, M. (2008) Activated Carbon Modified with Different Chemical Agents as a Catalyst in the Dehydrogenation of Isopropanol. Catalysis Letters, 125, 145-153. http://dx.doi.org/10.1007/s10562-008-9536-z

[8] Ilyas, M. and Ikramullah (2004) Dehydrogenation of Cyclohexanol to Cyclohexanone Catalysed by $\mathrm{Y}_{2} \mathrm{O}_{3} / \mathrm{ZrO}_{2}$ : Activation Energy. Catalysis Communications, 5, 1-4. http://dx.doi.org/10.1016/j.catcom.2003.10.010

[9] Barbara, G.S. (2002) Effect of Additives on the Physiochemical and Catalytic Properties of Oxide Catalysts in Selective Oxidation. Topics in Catalysis, 21, 1-3. http://dx.doi.org/10.1023/A:1020577912420

[10] Sugunan, S. and Paul, A. (1998) Basicity and Catakytic Activity of $\mathrm{ZrO}_{2}-\mathrm{Y}_{2} \mathrm{O}_{3}$ Mixed Oxides in the Oxidation of Cyclohexanol. Reaction Kinetics and Catalysis Letters, 65, 343-348. http://dx.doi.org/10.1007/BF02475274

[11] Zaki, M.I., Hasan, M.A. and Pasupulety. L. (2001) In Situ FTIR Spectroscopic Study of 2-Propanol Adsorption and Catalytic Interaction on Metal-Modified Aluminas. Langmuir, 17, 4025-4034. http://dx.doi.org/10.1021/la001810r

[12] Qian, H., Miedziak, P.J., kesavan, L., Dimitratos, N., Sankar, M., et al. (2013) Switching-Off Toluene Formation in the Solvent-Free Oxidation of Benzyl Alcohol Using Supported Trimetallic Au-Pd-Pt Nanoparticales. Faraday Discussions, 162, 365-378. http://dx.doi.org/10.1039/c2fd20153d

[13] Sadiq, M., Razia., Sajid, H. and Zamin, G. (2014) Efficiency of Iron Supported on Porous Material (Prepared from Peanut Shell) for Liquid Phase Aerobic Oxidation of Alcohols. Modern Research in Catalysis, 3, 35-48. http://dx.doi.org/10.4236/mrc.2014.32006

[14] van Dam, H.E., Wisse, L.J. and van Bekkum, H. (1990) Platinum/Carbon Oxidation Catalysts: VIII. Selecting a Metal for Liquid-Phase Alcohol Oxidations. Applied Catalysis, 61, 187-197. http://dx.doi.org/10.1016/S0166-9834(00)82143-0

[15] Yamaguchi, K. and Mizuno, N. (2002) Supported Ruthenium Catalyst for the Heterogeneous Oxidation of Alcohols with Molecular Oxygen. Angewandte Chemie International Edition, 41, 4538-4542. http://dx.doi.org/10.1002/1521-3773(20021202)41:23<4538::AID-ANIE4538>3.0.CO;2-6

[16] Hronec, M., Cvengrosova, Z., Tulejy, J. and Ilavsky, J. (1990) Liquid-Phase Oxidation of Hydrocarbons and Alcohols Catalyzed by Heterogeneous Palladium and Platinum Catalysts. Studies in Surface Science and Catalysis, 55, 169-176. http://dx.doi.org/10.1016/S0167-2991(08)60146-9

[17] Hronec, M., Cvengrosova, Z. and Kizlink, J. (1993) Competitive Oxidation of Alcohols in Aqueous Phase Using Pd/C Catalyst. Journal of Molecular Catalysis, 83, 75-82. http://dx.doi.org/10.1016/0304-5102(93)87008-V

[18] Akada, M., Nakano, S., Sugiyama, T., Ichitoh, K., Nakao, H., Akita, M. and Moro-oka, Y. (1993) A Practical O $2^{-}$ Oxidation of Functionalized Alcohols Producing Carboxylic Acids Catalyzed by the Pd-C/Pb(OAc) 2 System. Bulletin of the Chemical Society of Japan, 66, 1511-1515. http://dx.doi.org/10.1246/bcsj.66.1511

[19] Kimura, H., Kimura, A., Kokubo, I., Wakisaka, T. and Mitsuda, Y. (1993) Palladium Based Multi-Component Catalytic Systems for the Alcohol to Carboxylate Oxidation Reaction. Applied Catalysis A: General, 95,143-169.

[20] Oi, R. and Takenaka, S. (1988) Selective Conversion of $m$-Hydroxybenzyl Alcohols to $m$-Hydroxybenzaldehyde. Chemistry Letters, 17, 1115-1116. http://dx.doi.org/10.1246/cl.1988.1115

[21] Hayashi, H., Sugiyama, S., Shigemoto, N., Miyaura, K., Tsujino, S., Kawashiro, K. and Uemura, S. (1993) Formation of an Intermetallic Compound $\mathrm{Pd}_{3}$ Te with Deactivation of Te/Pd/C Catalysts for Selective Oxidation of Sodium Lactate to Pyruvate in Aqueous Phase. Catalysis Letters, 19, 369-373. http://dx.doi.org/10.1007/BF00767080

[22] Mallat, T., Bodnar, Z., Baiker, A., Greis, O., Strubig, H. and Reller, A. (1993) Preparation of Promoted Platinum Catalysts of Designed Geometry and the Role of Promoters in the Liquid-Phase Oxidation of 1-Methoxy-2-Propanol. Journal of Catalysis, 142, 237-253. http://dx.doi.org/10.1006/jcat.1993.1204 
Scientific Research Publishing (SCIRP) is one of the largest Open Access journal publishers. It is currently publishing more than 200 open access, online, peer-reviewed journals covering a wide range of academic disciplines. SCIRP serves the worldwide academic communities and contributes to the progress and application of science with its publication.

Other selected journals from SCIRP are listed as below. Submit your manuscript to us via either submit@scirp.org or Online Submission Portal.
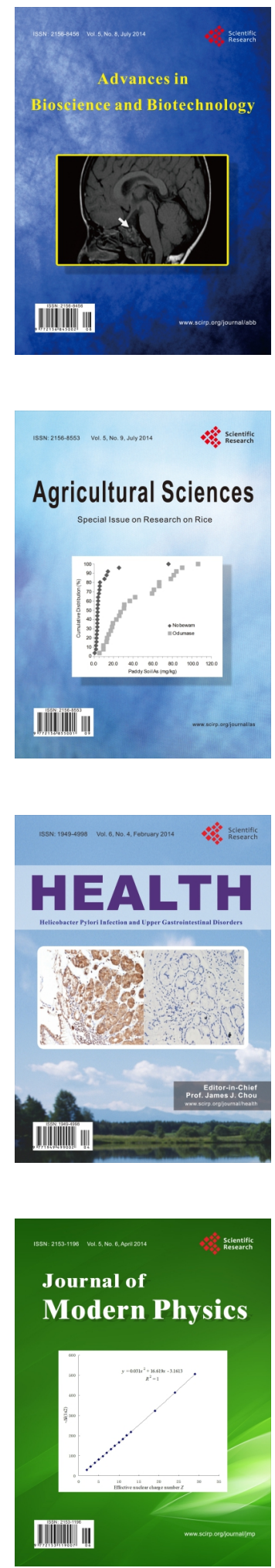
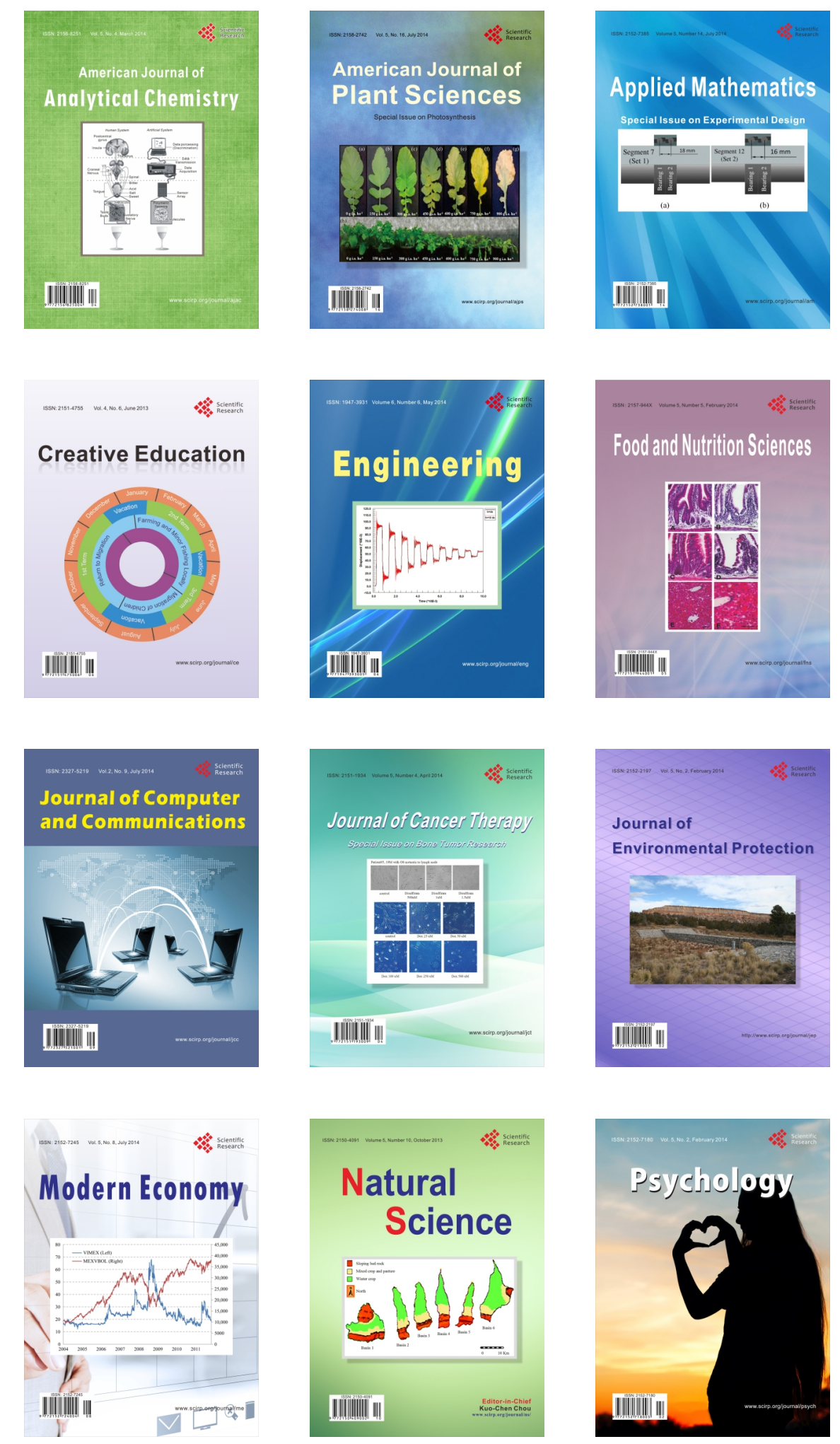